\title{
Resenha Constructivism in International Relations, the Politics of Reality
}

Maja Zehfuss. Cambridge, Cambridge University Press, 2002, 289 páginas.

\section{Mariana de Oliveira Barros*}

\begin{abstract}
A disciplina de Relações Internacionais vem passando por algumas mudanças bastante significativas desde o final dos anos 1980. A incapacidade das teorias tradicionais da área de preverem o fim surpreendentemente pacífico da Guerra Fria, a Guerra do Golfo e o desmantelamento da União Soviética colocou em questão os métodos de produção do conhecimento na disciplina (Gaddis, 1992:5).
\end{abstract}

A insatisfação com as teorias tradicionais, somada a questionamentos de ordem epistemológica, ontológica e metodológica que vinham acontecendo nas ciências humanas em geral, abriram espaço para que acontecesse na disciplina de Relações Internacionais o que foi chamado de "virada sociológica" (Katzenstein et alii, 1999:38), cuja principal característica é a introdução à área de perspectivas analíti-

\footnotetext{
*Mestranda em Relações Internacionais pelo Programa San Tiago Dantas de Pós-gradução em Relações Internacionais da PUC-SP/Unesp/Unicamp e professora de Relações Internacionais das Faculdades Tancredo Neves.
}

CONTEXTO INTERNACIONAL Rio de Janeiro, vol. 28, nº 1, janeiro/junho 2006, pp. 259-267. 
cas pós-positivistas, críticas ao pensamento racionalista tradicional nas teorias de relações internacionais.

As abordagens pós-positivistas distinguem-se das teorias racionalistas principalmente por proporem a idéia de que o mundo é socialmente construído, e não dado. Enquanto os racionalistas entendem uma realidade existente "lá fora", a qual tentam explicar a partir de uma metodologia positivista que julga possível a análise objetiva dos comportamentos, os pós-positivistas acreditam que a realidade está sempre em construção. Desconfiando dos métodos científicos utilizados para a explicação dos acontecimentos na política internacional, os pós-positivistas, em vez de tentar explicar, tentam interpretar, entender o mundo.

São diversas as abordagens pós-positivistas em Relações Internacionais. Entre as mais conhecidas, temos o construtivismo, o pós-modernismo, a teoria crítica e as teorias feministas (Smith, 2001:228). Por se propor um "caminho do meio" (Adler, 1999:205), uma "interseção" (Smith, 2001:242) entre os racionalistas e os pós-positivistas, o construtivismo é sem sombra de dúvida a corrente pós-positivista de maior aceitação entre os estudiosos da área, principalmente entre os representantes das correntes tradicionais.

O livro de Maja Zehfuss ora resenhado se propõe a discutir as aplicações do construtivismo para as análises das relações internacionais. Sendo a autora seguidora de uma linha pós-positivista considerada mais radical, a pós-estruturalista ou pós-moderna, seu livro é uma crítica ao construtivismo. A obra é indicada àqueles estudantes de Relações Internacionais que reconhecem o desenvolvimento das teorias pós-positivistas a partir da década de 1980 e a importância que elas vêm adquirindo na disciplina.

O principal argumento desenvolvido por Zehfuss em seu livro é que, ao tentar se colocar como meio-termo entre os racionalistas e os pós-positivistas, o construtivismo acaba por fazer concessões meto- 
dológicas que o afastam dos pós-positivistas e o aproximam das correntes tradicionais: "o famoso caminho do meio está muito mais perto do racionalismo do que dos pós-positivistas" $(: 5)^{1}$.

Para Zehfuss, o construtivismo é uma corrente que percebe a característica "construída" da realidade, mas que ainda assim define uma realidade a priori para iniciar suas análises. A instituição dessa realidade, mesmo que em última instância, é responsável por possibilitar o diálogo entre racionalistas e construtivistas. Não obstante, é também responsável pela perda da característica crítica a que se propõe o construtivismo.

Maja Zehfuss desenvolve também o argumento da "utilização estratégica do construtivismo" pelas correntes dominantes. Segundo a autora, quando representantes das correntes tradicionais abrem espaço para a aceitação de uma perspectiva analítica dita crítica, mas que ainda assim propõe um meio-termo, isentam-se de discutir as outras correntes críticas: "Logo, o construtivismo é importante não somente pelo papel de mediador que procura exercer, mas também pela possibilidade de ser utilizado estrategicamente para encobrir a necessidade de concessão de espaço para perspectivas mais radicais" $(: 6)$.

A autora utiliza para o desenvolvimento de sua crítica o exemplo da Alemanha e seu engajamento militar no exterior a partir do fim da Guerra Fria. Quando chamada a intervir no conflito do Golfo em 1991, a Alemanha recusou-se a participar, alegando que sua Constituição proibia o uso da força por tropas alemãs no exterior. No entanto, no ano de 1995, aceitou participar militarmente do processo de intervenção na Bósnia. Na tentativa de explicar essa mudança de comportamento na política externa alemã, Maja Zehfuss vai aplicar as análises de Alexander Wendt, Friedrich Kratochwil e Nicholas Onuf, os três principais autores construtivistas em Relações Internacionais, 
procurando mostrar as contradições internas dessas análises e as limitações de cada uma delas.

No caso de Wendt, a autora começa sua análise a partir da questão central do construtivismo, a identidade. Isto é, ela tenta explicar a mudança do comportamento alemão por meio da mudança da identidade alemã. No entanto, aponta para dois pontos críticos do construtivismo de Wendt. O primeiro é que, para ele, a mudança da identidade vem a partir de forças externas que fazem com que a identidade do país se modifique, ou seja, Wendt negligencia as questões internas. Ele faz uma clara separação entre a política externa e a doméstica, sendo a primeira responsável pelas mudanças na segunda. O segundo ponto é que, para Wendt, a identidade envolve expectativas estáveis quanto ao comportamento de um país. Para ele, a identidade é estável, ou é a realidade a priori a partir da qual as análises sobre o funcionamento das relações internacionais podem ser feitas (:61). A crítica de Zehfuss é que Wendt é incapaz de perceber as questões políticas que envolvem a própria construção das identidades. Ao tomar a identidade como realidade última, Wendt deixa de lado questões como: de que identidade estamos falando? A quem interessa a tomada dessa identidade como realidade? Zehfuss procura mostrar como até mesmo a opção por determinada identidade em detrimento de outra é, no fim, uma manifestação político-normativa (:87).

Com relação ao construtivismo de Kratochwil, a autora é menos enfática quanto às contradições internas do pensamento do autor, mas o critica por não ter levado até o fim a desconstrução do papel das normas na política. Kratochwil é conhecido por sua crítica à pobreza epistemológica da disciplina de Relações Internacionais. Ele dá grande destaque ao papel da linguagem na formação dos conceitos e suas análises estão sempre voltadas para as regras e normas que organizam a vida política. Segundo Kratochwil, as normas influenciam a conduta humana; portanto, estudando as normas, poderemos compreender o comportamento humano. Para tanto, ele parte do pressu- 
posto habermasiano de racionalidade que acredita em um "senso comum", ou entendimento intersubjetivo, que permite o estabelecimento de tais normas. Nesse sentido, para tentar entender a mudança do comportamento alemão em relação às intervenções militares sob a ótica do construtivismo de Kratochwil, Maja Zehfuss parte para uma análise da constituição alemã e de seus efeitos sobre o comportamento dos políticos alemães.

Diferentemente do que nos faria crer o pensamento de Kratochwil, Zehfuss revela que mesmo o entendimento intersubjetivo que leva ao estabelecimento e entendimento das normas é uma questão de escolha política. Isto porque as normas podem ser interpretadas de diferentes maneiras e a escolha por determinada interpretação em detrimento de outra está ligada à força política de imposição de uma norma, ou conduta ética, como a mais apropriada. Como podemos entender a conduta humana pelas normas se as normas podem ser entendidas de diversas maneiras (:117)? Isto é, Zehfuss argumenta que a intersubjetividade não é uma ferramenta política neutra, como Kratochwil parece nos apresentar, mas sim uma construção política. Para a autora, Kratochwil, ao entender o "senso comum" como realidade a priori, separa o normativo do político e rende-se à política da realidade, mesmo que intersubjetiva.

O último construtivismo analisado por Zehfuss é o de Onuf, conhecido por sua intenção de criar um novo paradigma para a teoria de Relações Internacionais, que leve em conta seu caráter político, e por seu intenso envolvimento com as questões da linguagem. Até certo ponto da análise de Zehfuss, somos levados a acreditar que Onuf será capaz de resolver as questões não contempladas por Kratochwil. Mas não é o que acontece. Apesar de reconhecer que Onuf vai fundo nas questões de análise dos discursos que criam as "verdades", entre elas as normas e as regras, e por isso conseguir explicar as características políticas dessas supostas verdades, Zehfuss critica Onuf por entender como materiais os limites que determinam certas escolhas e não 
outras. "Não podemos construir qualquer coisa que quisermos, a realidade material é um limite" (Onuf apud Zehfuss:182). Ou seja, ainda que o construtivismo de Onuf trate das construções sociais, inclusive dos discursos que constroem as regras, o autor acredita que existe um limite material que determina a escolha de certas construções em detrimento de outras, enquanto que, para Zehfuss, inclusive os limites materiais são escolhas políticas. Ela mostra isso citando o exemplo de que mesmo em condições adversas, como o problema do exército alemão não estar apropriadamente armado (limite material), a escolha em 1995 foi pela intervenção. Logo, para Zehfuss, as condições materiais nem sempre são o problema (:183). Mais uma vez, a questão é política, ou de vontade política. "Ao nos apresentar a realidade material como um limite, Onuf tende a privilegiar o mundo como este nos é apresentado, isto é, Onuf privilegia o status quo" (:195).

No quinto capítulo, depois de feitas as críticas aos diferentes autores construtivistas, Maja Zehfuss expõe claramente o argumento que vem sendo trabalhado desde o início do livro: ainda que responsável por grandes mudanças na disciplina de Relações Internacionais por demonstrar o caráter construído da realidade social, o construtivismo sempre faz concessão para a existência de alguma realidade a priori, seja ela identidade, intersubjetividade ou fatores materiais. O construtivismo acaba por endossar a "política da realidade", defendida pelas correntes dominantes.

No intuito de construir possíveis caminhos, uma vez desconstruídas as análises construtivistas, Maja Zehfuss propõe-nos algumas soluções derridarianas para o combate à política da realidade. Entre elas, o que poderíamos chamar de política da responsabilidade viabilizada pela experimentação do impossível. Isto é, para a autora, quando alegamos a existência de uma realidade independente, de "um mundo lá fora", estamos na verdade tentando nos eximir da responsabilidade de criarmos uma realidade diferente daquela já existente. Só que esta 
realidade existente "lá fora" é sempre responsável por sustentar posições políticas particulares. A única solução seria, portanto, a experiência do impossível, daquilo que não existe, daquilo que estará sendo criado no momento da decisão e que não seja aplicação de soluções já pensadas. Para Zehfuss, "o construtivismo opera na base de aceitação da realidade como limite" (:246). A única forma de desvinculação desse limite é a superação das barreiras que entendemos como reais por meio de nossa libertação para pensar a possibilidade do (que nos parece em princípio) impossível. "A experiência do impossível nos é crucial, e, segundo Derrida, qualquer tentativa de nos abstermos dela nada mais é do que a negação da nossa responsabilidade para com o mundo" (:231).

O livro de Zehfuss é um livro bastante denso, que pode apresentar alguma dificuldade para os leitores não muito familiarizados com as novas perspectivas analíticas das Relações Internacionais. É também um empreendimento bastante ambicioso, já que se dispõe a criticar em um único grande fôlego os três principais nomes do pensamento construtivista da atualidade. Ainda assim, Maja Zehfuss consegue transmitir ao leitor de forma bastante didática uma nova abordagem das relações internacionais, abordagem essa que por vezes é negligenciada exatamente pela dificuldade inerente ao seu conteúdo.

No entanto, é importante perguntar até que ponto é viável tratar, em um mesmo livro, de três autores que, apesar de se denominarem construtivistas, possuem propostas de trabalho tão distintas umas das outras. É extremamente válida a demonstração das idéias construtivistas por meio do exemplo das mudanças na política externa alemã desde o pós-Guerra Fria, mas muitas idéias importantes que podem ser encontradas em Wendt, Kratochwil e Onuf acabam sendo deixadas de lado. Cabe ao leitor que se sentir atraído pelo pensamento pós-positivista procurar as obras desses autores e lhes dedicar uma leitura mais aprofundada. 
Não obstante, o livro de Zehfuss cumpre bem a tarefa de chamar a atenção para a abordagem das Relações Internacionais feita pela corrente pós-moderna. Devido ao grande sucesso que vem sendo alcançado pelos construtivistas entre as correntes dominantes das Relações Internacionais e, para utilizar uma idéia de Wendt, a identidade que foi imposta aos pós-modernos, que os caracteriza como radicais, a corrente pós-moderna ficou renegada ao gueto da relativização infrutífera. É verdade que não é fácil entender e aplicar as propostas da política do impossível mencionada por Zehfuss; e ainda mais difícilé sabermos exatamente o que ela nos pede quando fala da necessidade das "novas atitudes" (:258), mas não podemos negar o espaço aberto à construção de novas e inumeráveis realidades que o pós-modernismo nos oferece.

\section{Nota}

1. Todas as citações foram livremente traduzidas pela autora desta resenha.

\section{Referências Bibliográficas}

ADLER, Emanuel. (1999), “O Construtivismo no Estudo das Relações Internacionais”. Lua Nova, n 47, pp. 201-239.

GADDIS, John Lewis. (1992), "International Relations Theory and the End of the Cold War". International Security, vol. 17, n' 3, pp. 5-58.

KATZENSTEIN, P., KEOHANE, R. e KRASNER, S. (1999), "International Organization and the Study of World Politics", in P. Katzenstein, R. Keohane e S. Krasner (eds.), Exploration and Contestation in the Study of World Politics: A Special Issue of International Organization. Massachusetts, MIT Press. 


\section{Resenha}

SMITH, Steve. (2001), "Reflectivist and Constructivist Approaches to International Relations Theory", in J. Baylis e S. Smith (orgs.), The Globalization of World Politics: An Introduction to International Relations. Oxford, Oxford University Press. 